\title{
SUPERVISI AKADEMIK PEMBELAJARAN IPA MELALUI ICT BASED LESSON STUDY UNTUK MEMBANGUN LEARNING COMMUNITY GURU SD
}

\author{
Achmad Samsudin \\ Jurusan Pendidikan Fisika, FPMIPA Universitas Pendidikan Indonesia \\ Jl. Dr. Setiabudhi No. 229 Bandung 40154 \\ Email: achmadsamsudin@upi.edu
}

\begin{abstract}
Have conducted a study on academic supervision science learning through ICT based Lesson Study to develop a learning community for science teachers. This article was a written idea can be realized in learning science especially in elementary school. A community of learning among elementary science teachers needs to be developed in order to improve the quality of science teaching and student learning achievement in the schools. This idea is carried through descriptive method based on a literature review. Supervision programs are assessed and analyzed using a pattern of lesson study, combined with ICT based that can bridge between science teachers and lecturers in the schools are separated by distance and geographical location are difficult to reach and require large additional costs. Some advantages of academic supervision program of learning science through ICT based Lesson Study is to provide broad access to learning for among components such as science teachers, supervisors, principals and lecturers. Keywords: supervision of academic, science, ICT based Lesson Study, learning community.
\end{abstract}

ABSTRAK

Telah dilakukan suatu kajian tentang supervisi akademik pembelajaran IPA melalui ICT Based Lesson Study untuk membangun learning community bagi guru IPA. Artikel ini merupakan sebuah gagasan tertulis yang dapat diwujudkan dalam pembelajaran IPA khususnya di SD. Sebuah komunitas belajar diantara guru IPA SD perlu dibangun guna meningkatkan kualitas pembelajaran IPA dan hasil belajar siswa di lapangan. Gagasan ini dilakukan melalui metode deskriptif berdasarkan kajian literatur. Program supervisi yang dikaji dan dianalisis menggunakan pola lesson study yang dipadukan dengan ICT based yang dapat menjembatani antar guru IPA dan dosen pendamping di lapangan yang dipisahkan oleh jarak dan letak geografis yang sulit dijangkau maupun memerlukan biaya akomodasi yang besar. Kelebihan program supervisi akademik pembelajaran IPA melalui ICT based lesson Study yaitu dapat memberikan akses belajar yang luas antar komponen seperti sesama guru IPA, pengawas, kepala sekolah, dan dosen pendamping.

Kata kunci: supervisi akademik, IPA, ICT based lesson study, learning community.

PENDAHULUAN Kualitas pendidikan di Indonesia banyak mendapatkan sorotan akhirakhir ini. Khusus mengenai IPA (IPA) yang akan menjadi sorotan kajian selanjutnya. Rendahnya capaian siswa dalam UAN dan hasil studi komparasi antar negara, merupakan salah satu indikator rendahnya kualitas pendidikan di Indonesia. Rendahnya capaian siswa Indonesia dikuatkan pula oleh laporan TIMMS yang memaparkan bahwa kemampuan matematika siswa di Indonesia berada pada urutan 34 dari 38 negara peserta, dan jauh di bawah kemampuan rata-rata secara internasional, begitu juga dengan kemampuan IPA (IPA) siswa dalam posisi ke 32 dari jumlah peserta yang sama (Mullis et al, 2000). Ana (2011) mengatakan dalam blog UMY bahwa dalam hal prestasi, 15 September 2004 lalu United Nations for Development Programme (UNDP) juga telah mengumumkan hasil studi tentang kualitas manusia secara serentak di seluruh dunia melalui laporannya yang berjudul Human Development Report 2004. Di dalam laporan tahunan ini Indonesia hanya menduduki posisi ke-111 dari 177 negara. Apabila dibanding dengan negara-negara tetangga saja, posisi Indonesia berada jauh di bawahnya. Selain itu, anak-anak Indonesia ternyata hanya mampu 
menguasai $30 \%$ dari materi bacaan dan ternyata mereka mengalami kesulitan dalam menjawab soal-soal berbentuk uraian yang memerlukan penalaran. Hal ini lebih disebabkan karena mereka sangat terbiasa menghafal dan mengerjakan soal pilihan ganda.

Kualitas pendidikan ditentukan oleh banyak faktor, di antaranya kurikulum, guru, fasilitas, dan masyarakat. Kurikulum di Indonesia telah beberapa kali mengalami perubahan, yang masih hangat dibicarakan adalah menjelang perubahan kurikulum di tahun 2013 ini, namun rata-rata UN IPA siswa relatif rendah, meskipun telah didukung keikutsertaan masyarakat atau orang tua misalnya dengan dibentuknya dewan pendidikan dan komite sekolah. Dengan demikian, wajarlah jika guru sebagai ujung tombak pendidikan merupakan pihak yang paling disorot dalam capaian belajar siswa. Terlebih lagi, hasil Ujian Kompetensi Guru (UKG) hingga hari ketiga, tercatat 373.415 guru TK hingga SD/SMK telah mengikuti uji kompetensi guru. Dari hasil pengolahan terhadap 243.619 peserta UKG hari pertama dan kedua, nilai rata-rata sementara UKG tergolong rendah, hanya 44,5 dari skor maksimum 100.

Kenyataan di lapangan juga menunjukkan bahwa mata pelajaran IPA tidak disukai oleh siswa. Banyak siswa SD mengalami kesulitan belajar IPA. Mata pelajaran ini dianggap tidak menarik minat siswa dan kebanyakan siswa memperoleh hasil belajar IPA yang rendah, bahkan sangat rendah. Analisis terhadap permasalahan ini mengarahkan temuan pada akar permasalahan yaitu bahwa sumber kesulitan tersebut disebabkan oleh sebagian besar guru IPA SD kurang memanfaatkan media informasi digital seperti: internet, multimedia interaktif, dan e-learning dalam pembelajaran IPA di kelas mereka, sehingga pengetahuan mereka tentang IPA menjadi sepotong-sepotong (partial) dan kurang kreatif dalam mencari sumber belajar dan sharing belajar dengan bantuan TIK (Teknologi Informasi dan Komunikasi). Rendahnya pengetahuan IPA guru SD ditengarai sebagai penyebab rendahnya dan kurang disukainya IPA bagi siswa-siswi di sekolah karena pembelajaran IPA diselenggarakan secara tradisional.

Pembelajaran IPA biasanya dilakukan secara ceramah dan siswa cenderung menghafalkan banyak hukum, prinsip, prosedur, dalil, dan rumus yang berhubungan dengan konsep IPA, sehingga pengetahuan IPA siswa bersifat verbalistis dan kurang bermakna. Apalagi banyak konsep-konsep IPA yang abstrak menyebabkan siswa salah memaknainya dan mengalami miskonsepsi (Romberg \& Kaput: 1999; Silver: 1989; Koseki: 2001). Seperti telah disampaikan di atas, guru merupakan pihak yang paling disorot dalam capaian belajar siswa. Oleh karena itu muncul berbagai upaya untuk meningkatkan kemampuan profesional guru. Berdasarkan kondisi-kondisi di atas perlu dicarikan suatu alternatif solusi agar setiap guru memperoleh kesempatan layanan untuk meningkatkan profesionalismenya. Memang sudah berjalan salah satu forum guru untuk meningkatkan profesionalismenya, yaitu melalui kegiatan MGMP (Musyawarah Guru Mata Pelajaran) Bidang IPA. Akan tetapi, forum ini tidak lebihnya sekedar ajang kumpul dan agenda besarnya hanya menyusun soal ujian semester bersama. Jarang sekali yang membicarakan dan mengeksplorasi praktikum IPA dan membahas konsep-konsep dalam pembelajaran IPA yang lebih interaktif dan inkuiri. Alternatif solusi yang ditawarkan adalah pemanfaatan teknologi informasi dan komunikasi (TIK) atau ICT dalam upaya peningkatan profesionalisme guru IPA SD menggunakan ICT based Lesson Study.

Secara umum kegiatan ini betujuan untuk membentuk learning community (komunitas belajar) dan meningkatkan kualitas pendidikan IPA di Jawa Barat. Secara khusus, kegiatan ini bertujuan untuk meningkatkan:

a. Jangkauan layanan profesional kepada guruguru SD.

b. Pemahaman konsep IPA bagi guru-guru SD.

c. Kemampuan pedagogi guru SD dalam pembelajaran IPA.

d. Kemampuan guru IPA dalam menggunakan ICT.

e. Kemampuan guru IPA SD dalam melaksanakan PTK dan menghasilkan karya tulis ilmiah.

f. Kemampuan guru SD dalam melakukan inovasi dalam pembelajaran IPA.

Metode kajian literatur yang digunakan adalah studi literatur dengan mendeskripsikan segala pemikiran dan gagasan yang terkait dengan supervisi akademik pembelajaran IPA 
melalui ICT based lesson study dalam rangka membangun komunitas belajar guru IPA SD.

\section{VISUALISASI MODEL ICT BASED LESSON STUDY}

Visualisasi model ICT based Lesson Study dapat dilihat dalam kerangka dasar peningkatan kualitas pembelajaran IPA SD di Jawa Barat seperti Gambar 1 berikut.



Gambar 1. Visualisasi Model ICT Based Lesson Study terhadap Guru IPA SD

Kegiatan ini terdiri dari 4 tahap, yaitu analisis kebutuhan (need assessment), pelatihan untuk guru, monitoring, dan evaluasi.

(1) Analisis Need Assessment (Base Line)

Pada tahap ini instrumen yang digunakan meliputi lembar tes siswa, pedoman wawancara, lembar observasi, dan angket.

(2) Pelatihan

Pelatihan untuk guru meliputi pengenalan materi, penjelasan teknis, PTK, KTI, serta komunikasi, diskusi, dan konsultasi melalui ICT.
(3) Monitoring

Monitoring dilaksanakan terhadap pelaksanaan kegiatan pembelajaran. Monitoring diperlukan sebagai refleksi dan evaluasi pelaksanaan program yang sedang berjalan.

(4) Evaluasi Program (End Line).

Evaluasi program meliputi program evaluasi yang diterapkan untuk mengetahui sejauh mana program ini dilaksanakan secara efektif. Ruang lingkup kegiatan ini meliputi:

1) Identifikasi kebutuhan (need assessment) 
2) Penentuan kelompok sasaran.

3) Pengembangan instrumen

4) Validasi, penyempurnaan, dan penggandaan instrumen.

5) Pengembangan bahan ajar melalui Lesson Study (LS) secara online:

(Rencana Pelaksanaan LS online setiap hari Senin dan Rabu Jam 13.00-16.00)

(1) Materi IPA melalui internet (online).

(2) Pedagogi IPA melalui internet (online).

(3) Pengayaan materi IPA melalui MMI.

(4) Pengayaan pedagogi IPA melalui internet (online)

6) Membangun dan menguji coba infrastruktur ICT/TIK.

7) Pelatihan: (1) Pengenalan ICT (Moodle)

(2) Penjelasan teknis

(3) Pelatihan PTK dan KTI

(4) Komunikasi, diskusi, dan konsultasi melalui ICT.

8) Monitoring pelaksanaan pembelajaran IPA dan refleksinya.

9) Pengumpulan dan analisis data.

10)Pelaporan.
Untuk lebih menggambarkan kerangka dasar dari ICT based Lesson Study tersebut dapat diuraikan dalam komponen-komponen model yang terkait di dalamnya. Komponen-komponen yang terlibat dalam model ICT based Lesson Study meliputi pihak internal dan eksternal dari sekolah, antara lain:

1. Guru IPA

2. Pengawas Sekolah Bidang IPA

3. Kepala Sekolah

4. Dosen

5. Siswa

6. Staf Sekolah yang lain

\section{HUBUNGAN ANTAR KOMPONEN}

Komponen-komponen yang dianggap sangat berperan dalam sistem penjaminan mutu pendidikan IPA terutama di persekolahan mempunyai peran dan tanggungjawab masingmasing dan saling mendukung. Secara singkat dapat digambarkan hubungan antar komponen antara lain: Perguruan Tinggi (Dosen), Sekolah (Siswa, Guru, Kepala Sekolah, dan Staf lain), dan Dinas Pendidikan (Pengawas Sekolah) melalui Gambar 2.

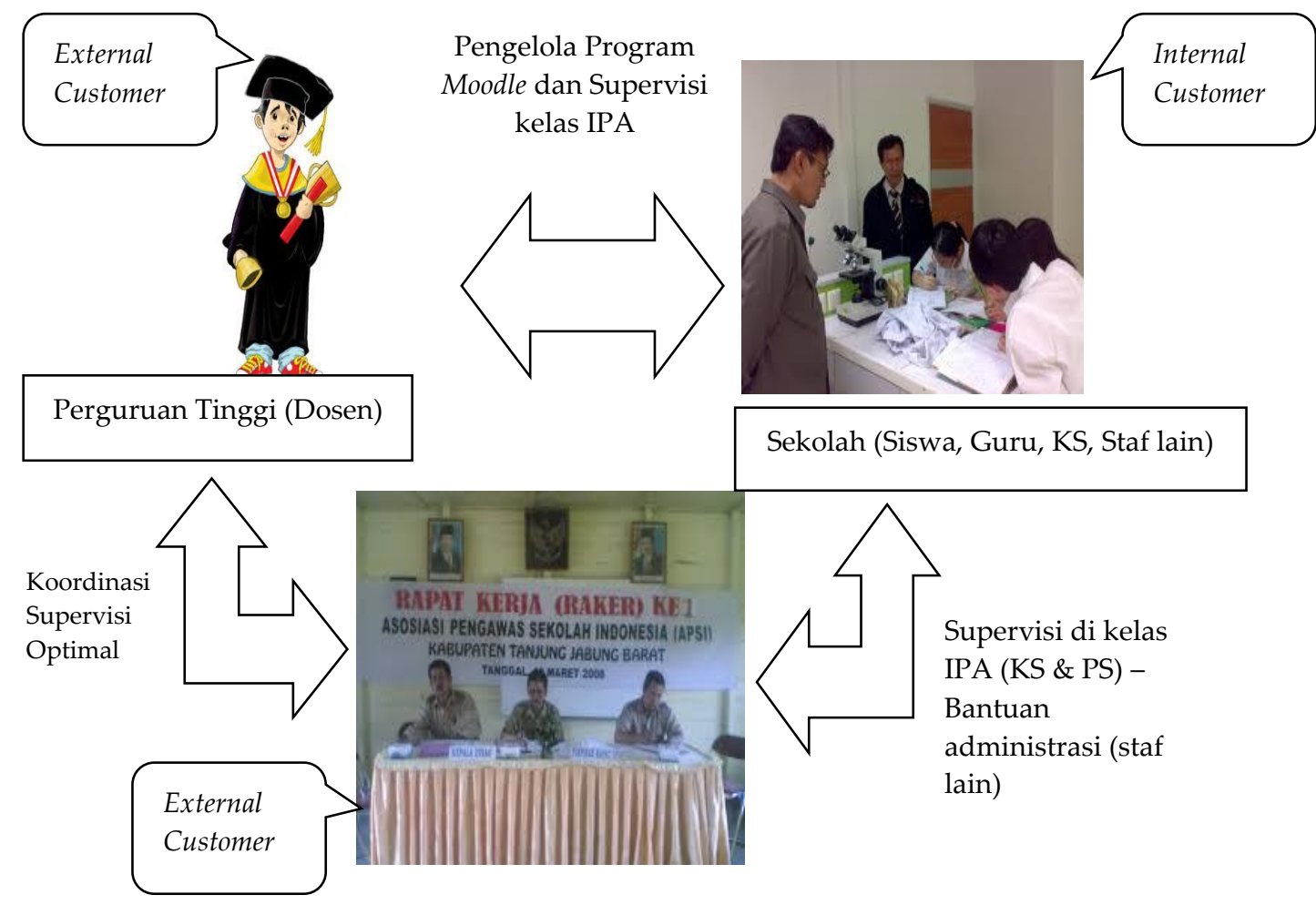

Dinas Pendidikan (Pengawas)

Gambar 2. Hubungan antar Komponen Model ICT based Lesson Study 
Berdasarkan Permendiknas No. 16 Tahun 2007 seorang guru dituntut memiliki empat kompetensi: pedagogi, kepribadian, sosial, dan profesional. Profesionalisme guru dinilai berdasarkan Permendiknas No. 18 Tahun 2007 terdiri dari uraian tentang:

a. kualifikasi akademik;

b. pendidikan dan pelatihan;

c. pengalaman mengajar;

d. perencanaan dan pelaksanaan pembelajaran;

e. penilaian dari atasan dan pengawas;

f. prestasi akademik;

g. karya pengembangan profesi;

h. keikutsertaan dalam forum ilmiah;

i. pengalaman organisasi di bidang kependidikan dan sosial; dan

j. penghargaan yang relevan dengan bidang pendidikan.

Pengawas berperan sebagai peneliti, konsultan atau penasehat, fasilitator, motivator, dan pelopor. Pengawasan bisa berwujud: memperhatikan, mengerti dan memahami, membantu dan membimbing, memupuk evaluasi diri bagi perbaikan dan pengembangan, memupuk kepercayaan diri dan memupuk, mendorong bagi pengembangan inisiatif dan kreativitas (Satori, 2012).

Siswa sebagai subjek pembelajaran menjadikan pembelajaran lebih bermakna manakal siswa benar-enar terlibat dalam pembelajaran. Sebagai contoh, guru melakukan pembelajaran berbasis inkuiri bebas dan problem solving. Guru SD pembelajar IPA hanya menyediakan alat dan bahan berupa silet, magnet, benang, dan tempat air disertai LKS yang tidak membimbing secara penuh apa yang siswa lakukan dalam mengeksplorasi konsep kemagnetan. Siswa dengan bekerja secara berkelompok mulai melakukan eksplorasi dan pengamatan sedangkan peran guru memfasilitasi siswa belajar dan membimbing jika dalam proses eksplorasi kemagnetan siswa mengalami kesulitan.

Kepala Sekolah, Pengawas, dan Dosen yang terlibat dalam kegiatan pembelajaran berupaya menjadi observer yang baik tanpa melakukakn intervensi terhadap pembelajaran yang sedang berlangsung. Customer eksternal ini melakukan supervisi dan melakukan refleksi dengan memberikan masukan yang positif untuk kemajuan pembelajaran di pertemuan berikutnya secara berkelanjutan.

\section{STRATEGI IMPLEMENTASI}

Lesson Study (LS) yang sukses adalah LS yang dapat meningkatkan profesionalisme guru, maka pelaksanaan LS secara berkesinambungan diyakini dapat meningkatkan praktik-praktik pembelajaran sehari-hari. Peningkatan praktikpraktik pembelajaran akan bermuara pada peningkatan kualitas proses dan produk belajar siswa. Secara umum pelaksanaan Lesson Study melalui tiga fase yaitu Plan, Do, dan See seperti Gambar 3 di bawah.

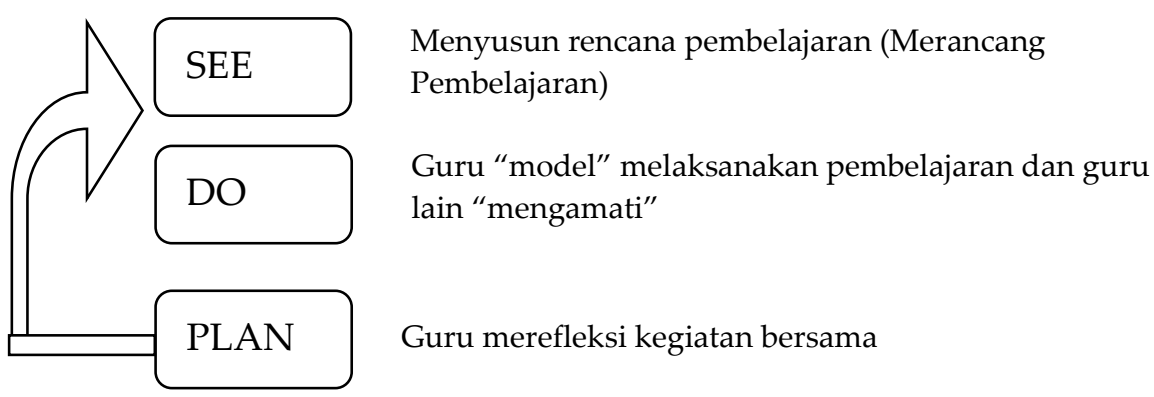

Gambar 3. Tahap-tahap Lesson Study (JICA, 2009)

Dalam pembelajaran IPA, secara operasional ICT based LS dapat dilaksanakan melalui 7 (tujuh) tahapan diadaptasi dari Santyasa (2009), yaitu (1) Menyiapkan program Moodle yang terintegrasi dengan program Skype. (2) Membentuk kelompok ICT based LS, (3) Memfokuskan kegiatan ICT based LS, (4) Merencanakan pembelajaran dan PTK, (5) Membelajarkan dan mengamati pembelajaran IPA serta melakukan 
PTK, (6) Merefleksikan dan menganalisis PTK, dan (7) Merencanakan kembali ICT based LS.

\section{SIMPULAN}

Pengawasan (Supervisi) oleh kepala sekolah, pengawas satuan pendidikan, dan dosen perguruan tinggi, hendaknya memahami tentang hakikat sains inkuiri dan mengikuti prinsipprinsip Lesson Study seperti kolegialitas. Sehingga evaluasi dan pengawasan yang dilakukan tidak mengarah kepada penghakiman atas pembelajaran guru melainkan dapat digunakan sebagai refleksi berkelanjutan terhadap pembelajaran IPA di Kelas. Pengawasan terus menerus, menghasilkan refleksi yang diimplementasikan terus menerus melalui fase LS yaitu PLAN, DO, dan SEE yang selalu berulang, sehingga budaya mutu (culture quality) melalui terciptanya Learning Community berlaku untuk semua komponen penyelenggara pendidikan dan mutu bukan suatu tujuan tetapi suatu proses.

\section{REFERENSI}

Ana. (2011). Penyebab Rendahnya Kualitas Pendidikan di Indonesia. [Online]. Tersedia: http://blog.umy.ac.id/anadwiwahyuni/pendid ikan/penyebab-rendahnya-kualitaspendidikan-di-indonesia/. [4 Januari 2013].
JICA. (2009). Panduan untuk Lesson Study Berbasis MGMP dan Lesson Study Berbasis Sekolah. Jakarta: Depdiknas, Depag, dan JICA.

Mullis, I.V.S, et al. (2000). TIMMS 1999, (p. 32). Boston: The International Study Center Boston College, Lynch School of Education.

Permendiknas RI No. 16. (2007). Kompetensi Guru. Jakarta: Kemdiknas.

Permendiknas RI No. 18. (2007). Tugas Guru dan Pengawas. Jakarta: Kemdiknas.

Romberg, T.A \& Kaput, J.J. (1999). Mathematics worth teaching, mathematics worth understanding. In Elizabeth Fennema \& Thomas A. Romberg (Eds.), Mathematics classroom that promote understanding, (pp.3-17). New Jersey: Lawrence Erlbaum Associates Publishers.

Santyasa, I. (2009). Implementasi Lesson Study dalam Pembelajaran. Makalah: Disajikan dalam "Seminar Implementasi Lesson Study dalam Pembelajaran bagi Guru-Guru TK, Sekolah Dasar, dan Sekolah Menengah Pertama di Kecamatan Nusa Penida, Tanggal 24 Januari 2009, di Nusa Penida.

Satori, D. (2012). Sistem Penjaminan dan Peningkatan Mutu Pendidikan. Makalah tidak diterbitkan. 